\title{
Communities of Learning
}

New Zealand Journal of Teachers' Work, Volume 14, Issue 1, 6-7, 2017

\author{
CLARE CURTICE \\ Mairangi Bay School
}

Since the late 1990s neoliberal economic policy has increasingly standardised educational assessment and curriculum, positioning the learner in an educational setting as a consumer, a unit of the economy, to be processed and utilised for the good of the market. Schools have narrowed their focus to teach what can be measured, so that the state can be assured that learners are prepared and processed against these criteria to enter the workforce. Debate around what education is for is couched in economic terms, with talk of clients and stakeholders, rather than as providers of a vision of the 'common good', and an understanding that what an education is for might be to create happier, healthier people. The language of business has been transcribed over the language of teaching and learning.

Investing in Educational Success is a 2014 policy of the National-led New Zealand government, with the vision that clusters of schools working together in 'communities of learning' would be the best way to improve educational outcomes for all. The aim of the policy is to promote collaboration between schools in the cluster, though for the Education Review Office, the evaluation of learner outcomes (or student achievement measurement processes) would define the success of the Communities of Learning: ERO seeks to evaluate the "intended outcomes of strengthening educational leadership and teaching practice to improve progress, achievement and long-term outcomes for all learners" (2016, "Key Evaluation Questions").

Adjusting teaching and learning for improvement leaves out any discussion about what schools should teach, or what measurement tools are reliable and accurate for schools, and at what grades or ages of schooling these subjects are most appropriate. The concepts of community and collaboration are hard to argue with. Some (such as Hargreaves,1994) have questioned collaboration, for the tension between the imperative to be like everyone else and the threat that not being part of the group can lead to alienation and exclusion. Otherwise, a diverse community can be so inclusive as to stand for everything and therefore nothing at all (Benade, 2017; Freire, 1970). Arguably, some implications that may arise from these tensions include learning either because of the contributions of other people, or simply reiterating what is acceptable to the dominant ideas of the social group. The former outcome may be desirable for collaborative improvement in education; the latter is highly undesirable. Ultimately, where the power and influence lies in the community will affect the direction and outcomes of this collaboration.

The 'communities of learning' initiative has the potential to strengthen the understandings between schools of assessment protocols, transitions between primary, intermediate and secondary schools, and the sharing of best practice in 
teaching. A considered approach is required, however, in regards to implementation and to develop a clear understanding of leadership theory and strategic planning. These steps will be critical to building trust from the outset. Furthermore, notions of the minimum workload expectations of potential CoL leaders also require careful consideration if the CoL policy is to provide real pathways. A failure in these respects is likely to result in a loss of trust in the value of the CoL policy.

\section{REFERENCES}

Benade, L. (2017). Being a teacher in the 21st century: A critical New Zealand research study. Singapore: Springer.

Education Review Office [ERO]. (2016). Communities of Learning | Kāhui Ako. Retrieved 12 September 2017 from http://www.ero.govt.nz/how-eroreviews/communities-of-learning-kahui-ako/

Freire, P. (1970). Cultural action for freedom. Harmondsworth, United Kingdom: Penguin Education.

Hargreaves, A. (1994). Changing teachers, changing times: Teachers' work and culture in the postmodern age. Toronto, Canada: OISE Press. 